MSC 35A01, 35G20

DOI: $10.14529 / \mathbf{m m p} 180101$

\title{
THE CAUCHY PROBLEM FOR THE SOBOLEV TYPE EQUATION OF HIGHER ORDER
}

\section{A.A. Zamyshlyaeva, E.V. Bychkov}

South Ural State University, Chelyabinsk, Russian Federation

E-mail: zamyshliaevaaa@susu.ru, bychkovev@susu.ru

Of concern is the semilinear mathematical model of ion-acoustic waves in plasma. It is studied via the solvability of the Cauchy problem for an abstract complete semilinear Sobolev type equation of higher order. The theory of relatively polynomially bounded operator pencils, the theory of differentiable Banach manifolds, and the phase space method are used. Projectors splitting spaces into direct sums and an equation into a system of two equivalent equations are constructed. One of the equations determines the phase space of the initial equation, and its solution is a function with values from the eigenspace of the operator at the highest time derivative. The solution of the second equation is the function with values from the image of the projector. Thus, the sufficient conditions were obtained for the solvability of the problem under study. As an application, we consider the fourthorder equation with a singular operator at the highest time derivative, which is in the base of mathematical model of ion-acoustic waves in plasma. Reducing the model problem to an abstract one, we obtain sufficient conditions for the existence of a unique solution.

Keywords: semilinear Sobolev type equation of higher order; Cauchy condition; relatively polynomially bounded operator pencils; phase space method.

\section{Introduction}

Let $\Omega=(0, a) \times(0, b) \times(0, c) \subset \mathbb{R}^{3}$. In a cylinder $\Omega \times \mathbb{R}$ consider equation which arose in a theory of ion-acoustic waves in plasma [1]

$$
(\Delta-\lambda) u_{t t t t}+\left(\Delta-\lambda^{\prime}\right) u_{t t}+\alpha \frac{\partial^{2} u}{\partial x_{3}^{2}}=\Delta\left(u^{3}\right)
$$

with the Cauchy-Dirichlet conditions

$$
\begin{gathered}
u(x, 0)=u_{0}(x), \quad u_{t}(x, 0)=u_{1}(x), \\
u_{t t}(x, 0)=u_{2}(x), \quad u_{t t t}(x, 0)=u_{3}(x), \quad x \in \Omega, \\
u(x, t)=0, \quad(x, t) \in \partial \Omega \times \mathbb{R} .
\end{gathered}
$$

In suitable Banach spaces $\mathfrak{U}$ and $\mathfrak{F}$ mathematical model (1), (2) can be reduced to the Cauchy problem

$$
u^{(k)}(0)=u_{k}, \quad k=0,1, \ldots, n-1,
$$

for a semilinear Sobolev type equation of higher order

$$
A u^{(n)}=B_{n-1} u^{(n-1)}+B_{n-2} u^{(n-2)}+\ldots+B_{0} u+N(u),
$$


where $u^{(k)}$ is the time derivative of order $k$, the operators $A, B_{n-1}, B_{n-2}, \ldots, B_{0} \in$ $\mathcal{L}(\mathfrak{U} ; \mathfrak{F}), N \in C^{\infty}(\mathfrak{U} ; \mathfrak{F})$. By Sobolev type equations we mean those equations that are not solvable with respect to the highest time derivative in particular when the operator $A$ is not invertible. Such situations often arise when $\operatorname{ker} A \neq\{0\}$. Mathematical models representable in form (3), (4) will be called Sobolev type mathematical models of higher order.

It is known that the Cauchy problem (3) for Sobolev type equations is unsolvable in principle for arbitrary initial data $u_{0}, u_{1}, \ldots, u_{n-1}$. In our opinion, the most fruitful approach to the study of such equations is the phase space method developed by G.A. Sviridyuk and T.G. Sukacheva for the study of semilinear Sobolev type equations of the first order [2]. The essence of this method consists in reducing the singular equation (2) to a regular one, defined, however, not on the entire space, but on some subset containing admissible initial values, understood as the phase space of the original equation.

A theory of complete linear Sobolev type equations of higher order is presented in [3]. Semilinear Sobolev type equations of the first order were studied in [4,5]. Initial-boundary value problems for Sobolev type equations of the first and higher order find application in mathematical modelling $[6,7]$.

The aim of the work is to develop a method of analytical investigation of Sobolev type mathematical models of higher order. In addition to the phase space method, the methods of the theory of relatively polynomially bounded operator pencils [8] are also used. In this article we also rely on the theory of differentiable Banach manifolds [9].

\section{Theory of Relatively Polynomially Bounded Operator Pencils}

Let $\mathfrak{U}, \mathfrak{F}$ be Banach spaces and operators $A, B_{0}, B_{1}, \ldots, B_{n-1} \in \mathcal{L}(\mathfrak{U} ; \mathfrak{F})$. By $\vec{B}$ denote the pencil formed by operators $B_{n-1}, \ldots, B_{1}, B_{0}$. The sets $\rho^{A}(\vec{B})=\left\{\mu \in \mathbb{C}:\left(\mu^{n} A-\right.\right.$ $\left.\left.\mu^{n-1} B_{n-1}-\ldots-\mu B_{1}-B_{0}\right)^{-1} \in \mathcal{L}(\mathfrak{F} ; \mathfrak{U})\right\}$ and $\sigma^{A}(\vec{B})=\overline{\mathbb{C}} \backslash \rho^{A}(\vec{B})$ are called an $A$ resolvent set and an $A$-spectrum of the pencil $\vec{B}$ respectively. The operator-function of a complex variable $R_{\mu}^{A}(\vec{B})=\left(\mu^{n} A-\mu^{n-1} B_{n-1}-\ldots-\mu B_{1}-B_{0}\right)^{-1}$ with the domain $\rho^{A}(\vec{B})$ is called an $A$-resolvent of the pencil $\vec{B}$.

Definition 1. The operator pencil $\vec{B}$ is called polynomially bounded with respect to an operator $A$ (or polynomially A-bounded) if $\exists a \in \mathbb{R}_{+} \quad \forall \mu \in \mathbb{C} \quad(|\mu|>a) \Rightarrow\left(R_{\mu}^{A}(\vec{B}) \in\right.$ $\mathcal{L}(\mathfrak{F} ; \mathfrak{U}))$.

Remark 1. If there exists an operator $A^{-1} \in \mathcal{L}(\mathfrak{F} ; \mathfrak{U})$ then the pencil $\vec{B}$ is $A$-bounded.

In [10] A.A. Zamyshlyaeva received the necessary condition for the construction of projectors

$$
\int_{\gamma} \mu^{k} R_{\mu}^{A}(\vec{B}) d \mu \equiv \mathbb{O}, \quad k=0,1, \ldots, n-2,
$$

where the circuit $\gamma=\{\mu \in \mathbb{C}:|\mu|=r>a\}$.

Lemma 1. [10] Let the operator pencil $\vec{B}$ be polynomially A-bounded and condition (5) be fulfilled. Then the operators 


$$
P=\frac{1}{2 \pi i} \int_{\gamma} R_{\mu}^{A}(\vec{B}) \mu^{n-1} A d \mu, \quad Q=\frac{1}{2 \pi i} \int_{\gamma} \mu^{n-1} A R_{\mu}^{A}(\vec{B}) d \mu
$$

are projectors in spaces $\mathfrak{U}$ and $\mathfrak{F}$ respectively.

Denote $\mathfrak{U}^{0}=\operatorname{ker} P, \mathfrak{F}^{0}=\operatorname{ker} Q, \mathfrak{U}^{1}=\operatorname{im} P, \mathfrak{F}^{1}=\operatorname{im} Q$. According to lemma 1 $\mathfrak{U}=\mathfrak{U}^{0} \oplus \mathfrak{U}^{1}, \quad \mathfrak{F}=\mathfrak{F}^{0} \oplus \mathfrak{F}^{1}$. By $A^{k}\left(B_{l}^{k}\right)$ denote restriction of operators $A\left(B_{l}\right)$ on $\mathfrak{U}^{k}, k=0,1 ; l=0,1, \ldots, n-1$.

Theorem 1. [10] Let the operator pencil $\vec{B}$ be polynomially A-bounded and condition (5) be fulfilled. Then

(i) $A^{k} \in \mathcal{L}\left(\mathfrak{U}^{k} ; \mathfrak{F}^{k}\right), k=0,1$;

(ii) $B_{l}^{k} \in \mathcal{L}\left(\mathfrak{U}^{k} ; \mathfrak{F}^{k}\right), k=0,1, l=0,1, \ldots, n-1$;

(iii) operator $\left(A^{1}\right)^{-1} \in \mathcal{L}\left(\mathfrak{F}^{1} ; \mathfrak{U}^{1}\right)$ exists;

(iv) operator $\left(B_{0}^{0}\right)^{-1} \in \mathcal{L}\left(\mathfrak{F}^{0} ; \mathfrak{U}^{0}\right)$ exists.

Using theorem 1 construct operators $H_{0}=\left(B_{0}^{0}\right)^{-1} A^{0} \in \mathcal{L}\left(\mathfrak{U}^{0}\right), H_{1}=\left(B_{0}^{0}\right)^{-1} B_{1}^{0} \in$ $\mathcal{L}\left(\mathfrak{U}^{0}\right), \ldots, H_{n-1}=\left(B_{0}^{0}\right)^{-1} B_{n-1}^{0} \in \mathcal{L}\left(\mathfrak{U}^{0}\right)$ and $S_{0}=\left(A^{1}\right)^{-1} B_{0}^{1} \in \mathcal{L}\left(\mathfrak{U}^{1}\right), S_{1}=\left(A^{1}\right)^{-1} B_{1}^{1} \in$ $\mathcal{L}\left(\mathfrak{U}^{1}\right), \ldots, S_{n-1}=\left(A^{1}\right)^{-1} B_{n-1}^{1} \in \mathcal{L}\left(\mathfrak{U}^{1}\right)$.

Definition 2. Define the family of operators $\left\{K_{q}^{1}, K_{q}^{2}, \ldots, K_{q}^{n}\right\}$ as follows:

$$
\begin{gathered}
K_{0}^{s}=\mathbb{O}, s \neq n, K_{0}^{n}=\mathbb{I}, \\
K_{1}^{1}=H_{0}, K_{1}^{2}=-H_{1}, \ldots, K_{1}^{s}=-H_{s-1}, \ldots, K_{1}^{n}=H_{n-1}, \\
K_{q}^{1}=K_{q-1}^{n} H_{0}, K_{q}^{2}=K_{q-1}^{1}-K_{q-1}^{n} H_{1}, \ldots, K_{q}^{s}=K_{q-1}^{s-1}-K_{q-1}^{n} H_{s-1}, \ldots, \\
K_{q}^{s}=K_{q-1}^{n-1}-K_{q-1}^{n} H_{n-1}, q=1,2, \ldots
\end{gathered}
$$

The $A$-resolvent can be represented by a Laurent series [10]

$$
\begin{gathered}
\left(\mu^{n} A-\mu^{n-1} B_{n-1}-\ldots-\mu B_{1}-B_{0}\right)^{-1}=-\sum_{q=0}^{\infty} \mu^{q} K_{q}^{n}\left(B_{0}^{0}\right)^{-1}(\mathbb{I}-Q)+ \\
+\sum_{q=1}^{\infty} \mu^{-q}\left(\mu^{n-1} S_{n-1}+\cdots+\mu S_{1}+S_{0}\right)^{q} L_{1}^{-1} Q .
\end{gathered}
$$

Using this representation we classify the character of the point at infinity of the $A$ resolvent of the operator pencil $\vec{B}$.

Definition 3. The point $\infty$ is called

- a removable singularity of an $A$-resolvent of the pencil $\vec{B}$, if $K_{1}^{s} \equiv \mathbb{O}, s=1,2, \ldots, n$;

- a pole of order $p \in \mathbb{N}$ of an A-resolvent of the pencil $\vec{B}$, if $\exists p$ such that $K_{p}^{s} \not \equiv \mathbb{O}, s=$ $1,2, \ldots, n$, but $K_{p+1}^{s} \equiv \mathbb{O}, s=1,2, \ldots, n$;

- an essential singularity of an A-resolvent of the pencil $\vec{B}$, if $K_{q}^{n} \not \equiv \mathbb{O}$ for all $q \in \mathbb{N}$.

Further a removable singularity of an $A$-resolvent of the pencil $\vec{B}$ will be called a pole of order 0 for brevity. If the operator pencil $\vec{B}$ is polynomially $A$-bounded and the point 
$\infty$ is a pole of order $p \in\{0\} \cup \mathbb{N}$ of an $A$-resolvent of the pencil $\vec{B}$ then the operator pencil $\vec{B}$ is called polynomially $(A, p)$-bounded.

Theorem 2. [3] Let $A, B_{n-1}, \ldots, B_{1}, B_{0} \in \mathcal{L}(\mathfrak{U}, \mathfrak{F})$ and $A$ be a Fredholm operator. Then the following statements are equivalent:

(i) The lengths of all chains of the $\vec{B}$-adjoined vectors of the operator $A$ are bounded by number $(p+n-1) \in\{0\} \cup \mathbb{N}$ and the chain of length $(p+n-1)$ exists.

(ii) The operator pencil $\vec{B}$ is polynomially $(A, p)$-bounded.

\section{Banach Manifolds}

Let $\mathfrak{M}$ be a $C^{k}$-manifold modelled by a Banach space $\mathfrak{U}$. By $T \mathfrak{M}$ denote a tangent bundle of the manifold $\mathfrak{M}$ and by $T^{n} \mathfrak{M}$ denote a tangent bundle of order $n$. The set $T \mathfrak{M}$ has the structure of a smooth $C^{k-1}$-manifold, modelled by Banach space $\mathfrak{U}$ by construction, and tangent bundle $T^{n} \mathfrak{M}$ is a manifold of class $C^{k-n}$. Further we assume that $k>n$.

By $\pi^{l}$ denote a canonical projection from a tangent bundle of order $l$ to a tangent bundle of order $l-1$ where $l=1,2, \ldots, n$ and by $\pi_{*}^{l}$ denote projection from tangent bundle of order $l$ to a manifold $\mathfrak{M}$, i.e. $\pi_{*}^{l}=\pi^{1} \pi^{2} \ldots \pi^{l}$.

Consider a curve $\alpha: J \rightarrow \mathfrak{M}$ of class $C^{s},(s \leq k)$ where $J$ is some interval containing zero. By canonical lifting of the curve $\alpha$ we call a curve $\alpha^{1}$ in $T \mathfrak{M} \alpha^{1}: J \rightarrow T \mathfrak{M}$ such that $\pi^{1} \alpha^{1}=\alpha$. Similarly, by the lifting of order $l$ of curve $\alpha$ in $T^{l} \mathfrak{M}$ we call a curve $\alpha^{l}: J \rightarrow T^{l} \mathfrak{M}$ such that $\pi_{*}^{l} \alpha^{l}=\alpha$. Therefore lifting of order $l$ of the curve is a mapping of class $s-l \geq 1$.

On the basis of the definition of a second-order differential equation [9] introduce

Definition 4. A differential equation of order $n$ on a manifold $\mathfrak{M}$ is a vector field $\xi$ of class $C^{k-n}$ on the tangent bundle $T^{n-1} \mathfrak{M}$ such that for all $v \in T^{n-1} \mathfrak{M}$ the equality

$$
\pi^{n} \xi(v)=v
$$

holds.

It follows from the definition that $\xi$ is a differential equation of order $n$ iff every integral curve $\beta$ for $\xi$ is a lifting of order $n-1$ of the curve $\pi_{*}^{n-1} \beta$. In other words

$$
\left(\pi_{*}^{n-1} \beta\right)^{n-1}=\beta
$$

Let $\mathfrak{M}$ be an open set in the Banach space $\mathfrak{U}$. In this case, for any vector field on $T^{n-1} \mathfrak{M}$, the main part of differential equation

$$
f: T^{n-1} \mathfrak{M} \rightarrow \mathfrak{U}^{n}
$$

has $n$ components $f=\left(f_{1}, f_{2}, \ldots, f_{n}\right)$ each of which maps $T^{n-1} \mathfrak{M}$ into $\mathfrak{U}$.

Lemma 2. [9] The mapping $f$ of class $C^{k-n}$ is the main part of a differential equation of order $n$ iff

$$
f\left(g_{1}, g_{2}, \ldots, g_{n}\right)=\left(g_{2}, g_{3}, \ldots, g_{n}, f_{n}\left(g_{1}, g_{2}, \ldots, g_{n}\right)\right) .
$$

Following [9] we formulate and prove 
Theorem 3. Let $\mathfrak{M}$ be a Banach $C^{k}$-manifold, $\xi$ be a differential equation of order $n$ of class $C^{k-n}$. Then for any point $\left(u_{0}, u_{1}, \ldots, u_{n-1}\right) \in T^{n-1} \mathfrak{M}$ there exists a unique curve $u \in C^{l}((-\tau, \tau) ; \mathfrak{M}), \tau=\tau\left(u_{0}, u_{1}, \ldots, u_{n-1}\right)>0, l \geq n$, lying in $\mathfrak{M}$, passing through the point $\left(u_{0}, u_{1}, \ldots, u_{n-1}\right)$ such that

$$
\begin{aligned}
u^{(n)} & =f_{n}\left(u, \dot{u}, \ddot{u}, \ldots, u^{(n-1)}\right), \\
u^{(k)}(0) & =u_{k}, \quad k=0,1, \ldots, n-1 .
\end{aligned}
$$

Proof. Since $T^{n-1} \mathfrak{M}$ is a $C^{k-n+1}$-manifold and $\xi$ is a vector field of class $C^{l}$ on $T^{n-1} \mathfrak{M}$, then for any point $\left(u_{0}, u_{1}, \ldots, u_{n-1}\right) \in T^{n-1} \mathfrak{M}$, there exists a unique integral curve $\varphi(t), t \in(-\tau, \tau)$, passing through the point $\left(u_{0}, u_{1}, \ldots, u_{n-1}\right)\left(\varphi(0)=\left(u_{0}, u_{1}, \ldots, u_{n-1}\right)\right)$. We represent a curve in the form of $n$ components and consider it locally

$$
\varphi(t)=\left(u(t), u_{1}(t), \ldots, u_{n-1}(t)\right) \in \mathfrak{M} \times \mathfrak{U}^{n-1} .
$$

By lemma 2, if $f$ is the main part of differential equation $\xi$, then

$$
\begin{aligned}
\dot{\varphi}= & \left(\dot{u}(t), \dot{u}_{1}(t), \ldots, \dot{u}_{n}(t)\right)=f\left(u(t), u_{1}(t), \ldots, u_{n-1}(t)\right)= \\
= & \left(u_{1}(t), \ldots, u_{n-1}(t), f_{n}\left(u(t), u_{1}(t), \ldots, u_{n-1}(t)\right)\right) .
\end{aligned}
$$

Therefore, the differential equation can be rewritten in more convenient form

$$
\begin{aligned}
& \dot{u}(t)=u_{1}(t) \\
& \dot{u}_{1}(t)=u_{2}(t) \\
& \ldots \\
& \dot{u}_{n-1}(t)=f_{n}\left(u(t), u_{1}(t), \ldots, u_{n-1}(t)\right)
\end{aligned}
$$

or $u^{(n)}(t)=f_{n}\left(u(t), u_{1}(t), \ldots, u_{n-1}(t)\right)$. Making the reverse substitution, we obtain

$$
u^{(n)}=f_{n}\left(u, \dot{u}, \ddot{u}, \ldots, u^{(n-1)}\right) .
$$

Thus, the curve $\left(\pi_{*} \varphi\right)(t)=u(t), t \in(-\tau, \tau)$, lies in $\mathfrak{M}$ and satisfies $(6)$.

\section{The Cauchy Problem}

Turn to problem (3), (4) and give definition of its solution.

Definition 5. If a vector-function $u \in C^{\infty}((-\tau, \tau) ; \mathfrak{U}), \tau \in \mathbb{R}_{+}$satisfies equation (4) then it is called a solution of this equation. If the vector-function satisfies in addition condition (3) then it is called a solution of (3), (4).

Definition 6. The set $\mathfrak{P}$ is called a phase space of (4), if

(i) for all $\left(u_{0}, u_{1}, \ldots, u_{n-1}\right) \in T^{n-1} \mathfrak{P}$ there exists a unique solution of (3), (4);

(ii) a solution $u=u(t)$ of (4) lies in $\mathfrak{P}$ as a trajectory, i.e. $u(t) \in \mathfrak{P}$ for all $t \in(-\tau, \tau)$.

If $\operatorname{ker} A=\{0\}$ then equation (2) can be reduced to an equivalent equation

$$
u^{(n)}=F\left(u, \dot{u}, \ldots, u^{(n-1)}\right),
$$


where $F\left(u, \dot{u}, \ldots, u^{(n-1)}\right)=A^{-1}\left(B_{n-1} u^{(n-1)}+B_{n-2} u^{(n-2)}+\ldots+B_{0} u+N(u)\right)$ is a mapping of class $C^{\infty}$ by construction. The existence of a unique solution $u$ of (3), (4) for all $\left(u_{0}, u_{1}, \ldots, u_{n-1}\right)$ follows from theorem 3 .

Let $\operatorname{ker} A \neq\{0\}$ and operator pencil $\vec{B}$ be $(A, 0)$-bounded, then by theorem 1 equation (4) can be reduced to an equivalent system of equations

$$
\left\{\begin{array}{c}
0=(\mathbb{I}-Q)\left(B_{0}+N\right)\left(u^{0}+u^{1}\right) \\
\frac{d^{n}}{d t^{n}} u^{1}=A_{1}^{-1} Q\left(B_{n-1} \frac{d^{n-1}}{d t^{n-1}}+B_{n-2} \frac{d^{n-2}}{d t^{n-2}}+\ldots+B_{0}+N\right)\left(u^{0}+u^{1}\right),
\end{array}\right.
$$

where $u^{1}=P u, u^{0}=(I-P) u$.

Now consider a set $\mathfrak{M}=\left\{u \in \mathfrak{U}:(I-Q)\left(B_{0} u+N(u)\right)=0\right\}$. Let the set $\mathfrak{M}$ be not empty, i.e. there is a point $u_{0} \in \mathfrak{M}$. Denote $u_{0}{ }^{1}=P u \in \mathfrak{U}^{1}$.

The set $\mathfrak{M}$ is called a Banach $C^{k}$-manifold at point $u_{0}$ if there exist neighborhoods $\mathcal{O} \subset \mathfrak{M}$ and $\mathcal{O}^{1} \subset \mathfrak{U}^{1}$ of points $u_{0}$ and $u_{0}^{1}$ respectively and a $C^{k}$-diffeomorphism $\delta: \mathcal{O}^{1} \rightarrow \mathcal{O}$ such that $\delta^{-1}$ is a restriction of projector $P$ on $\mathcal{O}$. The set $\mathfrak{M}$ is called a Banach $C^{k_{-}}$ manifold modelled by the space $\mathfrak{U}^{1}$ if it is a Banach $C^{k}$-manifold at any point. Connected $C^{k}$-manifold is simple if any atlas is equivalent to an atlas including only one map.

Let the following condition be fulfilled

$$
(\mathbb{I}-Q)\left(B_{0}+N_{u_{0}}^{\prime}\right): \mathfrak{U}^{0} \rightarrow \mathfrak{F}^{0} \text { is a toplinear isomorfism. }
$$

According to the implicit function theorem [11] there exist neighborhoods $\mathcal{O}^{0} \subset \mathfrak{U}^{0}$ and $\mathcal{O}^{1} \subset \mathfrak{U}^{1}$ of points $u_{0}^{0}=(\mathbb{I}-P) u_{0}, u_{0}^{1}=P u_{0}$ respectively and the operator $B \in C^{\infty}\left(\mathcal{O}^{1} ; \mathcal{O}^{0}\right)$ such that $u_{0}^{0}=B\left(u_{0}^{1}\right)$. Construct an operator $\delta=\mathbb{I}+B: \mathcal{O}^{1} \rightarrow \mathfrak{M}, \delta\left(u_{0}^{1}\right)=u_{0}$. Then the operator $\delta^{-1}$ together with the set $\mathcal{O}^{1}$ makes a map of $\mathfrak{M}$ and is a restriction of $P$ on $\delta\left[\mathcal{O}^{1}\right]=\mathcal{O} \subset \mathfrak{M}$. Thus we prove

Lemma 3. The set $\mathfrak{M}=\left\{u \in \mathfrak{U}:(\mathbb{I}-Q)\left(B_{0} u+N(u)\right)=0\right\}$ under condition (8) is a $C^{\infty}$-manifold at point $u_{0}$.

Lets act with the Frechet derivative $\delta_{\left(u_{0}^{1}, u_{1}^{1}, \ldots, u_{n-1}^{1}\right)}^{(n)}$ of order $n$ on the second equation of system (7). Since $\delta\left(u^{1}\right)=u$ and

$$
\delta_{\left(u_{0}^{1}, u_{1}^{1}, \ldots, u_{n-1}^{1}\right)}^{(n)} u^{1^{(n)}}=\frac{d^{n}}{d t^{n}}\left(\delta\left(u^{1}\right)\right)
$$

we obtain equation $u^{(n)}=F\left(u, \dot{u}, \ldots, u^{(n-1)}\right)$, where

$$
\begin{gathered}
F\left(u, \dot{u}, \ldots, u^{(n-1)}\right)=\delta_{\left(u_{0}^{1}, u_{1}^{1}, \ldots, u_{n-1}^{1}\right)}^{(n)} A^{-1} Q\left(B_{n-1} u^{(n-1)}+B_{n-2} u^{(n-2)}+\ldots\right. \\
\left.+B_{0} u+N(u)\right) \in C^{\infty}(\mathfrak{U}) .
\end{gathered}
$$

By virtue of theorem 3, we get

Theorem 4. Let the operator pencil $\vec{B}$ be $(A, 0)$-bounded, $N \in C^{\infty}(\mathfrak{U} ; \mathfrak{F})$ and condition (8) be fulfilled. Then for any $\left(u_{0}, u_{1}, \ldots, u_{n-1}\right) \in T^{n-1} \mathfrak{M}$ there exists a unique solution of (3), (4) lying in $\mathfrak{M}$ as trajectory. 


\section{Mathematical Model of Ion-Acoustic Waves in Plasma}

Turn to the model example (1), (2). In order to reduce (1), (2) to (3), (4) set

$$
\mathfrak{U}=\left\{u \in W_{2}^{l+2}(\Omega): u(x)=0, x \in \partial \Omega\right\}, \quad \mathfrak{F}=W_{2}^{l}(\Omega) .
$$

Define operators $A=\Delta-\lambda, B_{2}=\left(\lambda^{\prime}-\Delta\right), B_{0}=-\alpha \frac{\partial^{2}}{\partial x_{3}^{2}}, B_{3}=B_{1}=\mathbb{O}$. Operators $A, B_{3}, B_{2}, B_{1}, B_{0}$ are $\in \mathcal{L}(\mathfrak{U} ; \mathfrak{F})$ for all $l \in\{0\} \cup \mathbb{N}$.

Denote the eigenfunctions of the Dirichlet problem (2) for the Laplace operator by $\varphi_{k m n}=\left\{\sin \frac{\pi k x_{1}}{a} \sin \frac{\pi m x_{2}}{b} \sin \frac{\pi n x_{3}}{c}\right\}$, where $k, m, n \in \mathbb{N}$ and denote the eigenvalues by $\lambda_{k m n}=-\sqrt{\left(\frac{\pi k}{a}\right)^{2}+\left(\frac{\pi m}{b}\right)^{2}+\left(\frac{\pi n}{c}\right)^{2}}$. The spectrum $\sigma(\Delta)$ is negative, discrete, finite and tends only to $-\infty$. Since $\left\{\varphi_{k m n}\right\} \subset C^{\infty}(\Omega)$ we obtain

$$
\begin{gathered}
\mu^{4} A-\mu^{3} B_{3}-\mu^{2} B_{2}-\mu B_{1}-B_{0}= \\
=\sum_{k, m, n=1}^{\infty}\left[\left(\lambda_{k m n}-\lambda\right) \mu^{4}+\left(\lambda_{k m n}-\lambda^{\prime}\right) \mu^{2}-\alpha\left(\frac{\pi n}{c}\right)^{2}\right]<\varphi_{k m n}, \cdot>\varphi_{k m n},
\end{gathered}
$$

where $\langle\cdot, \cdot\rangle$ is the inner product in $L^{2}(\Omega)$.

Remark 2. In the case when (i) $\lambda \notin \sigma(\Delta)$ the $A$-spectrum of pencil $\vec{B} \sigma^{A}(\vec{B})=\left\{\mu_{r m n}^{j}\right.$ : $r, m, n \in \mathbb{N}, j=1, \ldots, 4\}$, where $\mu_{r m n}^{j}$ are the roots of equation.

$$
\left(\lambda_{r m n}-\lambda\right) \mu^{4}+\left(\lambda_{r m n}-\lambda^{\prime}\right) \mu^{2}-\alpha\left(\frac{\pi n}{c}\right)^{2}=0 .
$$

In the case when (ii) $(\lambda \in \sigma(\Delta)) \wedge\left(\lambda \neq \lambda^{\prime}\right)$ the $A$-spectrum of pencil $\vec{B} \sigma^{A}(\vec{B})=\left\{\mu_{l, k}^{j}\right.$ : $k \in \mathbb{N}\}$, where $\mu_{l, k}^{j}$ are the roots of equation (9) with $\lambda=\lambda_{l}$. In the case when (iii) $(\lambda \in \sigma(\Delta)) \wedge\left(\lambda=\lambda^{\prime}\right)$ the $A$-spectrum of pencil $\vec{B} \sigma^{A}(\vec{B})=\left\{\mu_{l, k}^{j}: k \in \mathbb{N}, k \neq l\right\}$.

Check condition (5). In case (i) there exists $A^{-1} \in \mathcal{L}\left(\mathfrak{F}^{1} ; \mathfrak{U}^{1}\right)$ therefore condition (5) is fulfilled [3].

In case (ii)

$$
\begin{gathered}
\frac{1}{2 \pi i} \int_{\gamma} \sum_{k, m, n=1}^{\infty} \frac{\mu^{r}<\varphi_{k m n},>\varphi_{k m n} d \mu}{\left(\lambda_{k m n}-\lambda\right) \mu^{4}+\left(\lambda_{k m n}-\lambda^{\prime}\right) \mu^{2}-\alpha\left(\frac{\pi n}{c}\right)^{2}}= \\
=\frac{1}{2 \pi i} \int_{\gamma} \sum_{k, m, n=1}^{\infty} \frac{\mu^{r}<\varphi_{k m n}, \cdot>\varphi_{k m n} d \mu}{\left(\lambda_{k m n}-\lambda^{\prime}\right) \mu^{2}-\alpha\left(\frac{\pi n}{c}\right)^{2}} \neq 0,
\end{gathered}
$$

when $r=1$, therefore condition (5) is not fulfilled and this case is excluded from further considerations. In case (iii) $(\lambda \in \sigma(\Delta)) \wedge\left(\lambda=\lambda^{\prime}\right)$ condition (5) is fulfilled.

Lemma 4. Let (i) $\lambda \notin \sigma(\Delta))$ or (ii) $(\lambda \in \sigma(\Delta)) \wedge\left(\lambda=\lambda^{\prime}\right)$. Then pencil $\vec{B}$ is polynomially $(A, 0)$-bounded.

Proof. In case (i) ker $A=\{0\}$ that is, the operator $A$ has no eigenvectors and, by remark 1 the pencil $\vec{B}$ is $(A, 0)$-bounded. 
In case (ii) $\lambda \in \sigma(\Delta)$ and $\lambda=\lambda^{\prime}$ construct the chain of $\vec{B}$-adjoined vectors of an eigenvector $\varphi_{0}=\sum_{\lambda=\lambda_{k m n}} a_{k m n} \varphi_{k m n} \in \operatorname{ker} A \backslash\{0\}$. Since $B_{3}=B_{1}=\mathbb{O}$ the first three $\vec{B}$-adjoined vectors can be taken equal to zero. On the fourth we obtain

$$
B_{0} \varphi_{0}=B_{0}\left(\sum_{\lambda=\lambda_{k m n}} a_{k m n} \varphi_{k m n}\right)=-\alpha\left(\frac{\pi n}{c}\right)^{2} \sum_{\lambda=\lambda_{k m n}} a_{k m n} \varphi_{k m n} \notin \operatorname{im} A,
$$

since $\sum_{\lambda=\lambda_{k m n}}\left|a_{k m n}\right|>0$.

Therefore the eigenvector $\varphi_{0}$ doesn't have a $\vec{B}$-adjoined vector of order four, the length of the chains of $\vec{B}$-adjoined vectors of operator $A$ is bounded by three, and the chain of length three exists.

Construct projectors. In case (i) $P=\mathbb{I}$ and $Q=\mathbb{I}$. In case (ii)

$$
P=\mathbb{I}-\sum_{\lambda=\lambda_{k m n}}<\varphi_{k m n},>\varphi_{k m n}
$$

and the projector $Q$ has the same form but it is defined on space $\mathfrak{F}$. Construct the set

$$
\mathfrak{M}=\left\{u \in \mathfrak{U}: \sum_{\lambda=\lambda_{k m n}}<\alpha\left(\frac{\pi n}{c}\right)^{2} u+\Delta\left(u^{3}\right), \varphi_{k m n}>\varphi_{k m n}=0\right\} .
$$

By theorem 4 we have

Theorem 5. (i) Let $\lambda \notin \sigma(\Delta),\left(u_{0}, u_{1}, \ldots, u_{n-1}\right) \in \mathfrak{U}^{n}$. Then for some $\tau=$ $\tau\left(u_{0}, u_{1}, \ldots, u_{n-1}\right)>0$ there exists a unique solution $u \in C^{n}((-\tau, \tau), \mathfrak{U})$ of problem (1), (2).

(ii) Let $(\lambda \in \sigma(\Delta)) \wedge\left(\lambda=\lambda^{\prime}\right),\left(u_{0}, u_{1}, \ldots, u_{n-1}\right) \in T^{n-1} \mathfrak{M}$ and condition (8) be fulfilled. Then for some $\tau=\tau\left(u_{0}, u_{1}, \ldots, u_{n-1}\right)>0$ there exists a unique solution $u \in C^{n}((-\tau, \tau), \mathfrak{M})$ of problem (1), (2).

Acknowledgment. The work was supported by Act 211 Government of the Russian Federation, contract no. 02.A03.21.0011.

\section{References}

1. Zamyshlyaeva A.A., Muravyev A.S. Computational Experiment for One Mathematical Model of Ion-Acoustic Waves. Bulletin of the South Ural State University. Series: Mathematical Modelling, Programming and Computer Software, 2015, vol. 8, no. 2, pp. 127-132.

2. Sviridyuk G.A., Sukacheva T.G. [The Phase Space of a Class of Operator Equations of Sobolev Type]. Differential Equations, 1990, vol. 26, no. 2, pp. 250-258. (in Russian)

3. Zamyshliaeva A.A. Lineynye uravneniya sobolevskogo tipa vysokogo poryadka [Linear Sobolev Type Equations of Higher Order]. Chelyabinsk, Publishing center of SUSU, 2012. (in Russian)

4. Sviridyuk G.A., Sukacheva T.G. Galerkin Approximations of Singular Nonlinear Equations of Sobolev Type. Russian Mathematics, 1989, vol. 33, no. 10. pp. 56-59. 
5. Manakova N.A., Bogatyreva E.A. On a Solution of the Dirichlet-Cauchy Problem for the Barenblatt-Gilman Equation. The Bulletin of Irkutsk State University. Series: Mathematics, 2014, vol. 7, pp. 52-60. (in Russian)

6. Manakova N.A., Dyl'kov A.G. Optimal Control of the Solutions of the Initial-Finish Problem for the Linear Hoff Model. Mathematical Notes, 2013, vol. 94, no. 1-2, pp. 220-230. DOI: $10.1134 /$ S0001434613070225

7. Keller A.V., Sagadeeva M.A. The Optimal Measurement Problem for the Measurement Transducer Model with a Deterministic Multiplicative Effect and Inertia. Bulletin of the South Ural State University. Series: Mathematical Modelling, Programming and Computer Software, 2014, vol. 7, no. 1, pp. 134-138. DOI: 10.14529/mmp140111 (in Russian)

8. Sviriduyk G.A., Zamyshlyaeva A.A. The Phase Space of a Class of Linear Higher Order Sobolev Type Equations. Differential Equations, 2006, vol. 42, no 2, pp. 269-278. DOI: $10.1134 /$ S0012266106020145

9. Leng S. Introduction to Differentiable Manifolds. N.Y., Springer, 2002.

10. Zamyshlyaeva A.A. The Phase Space of a High Order Sobolev Type Equation. The Bulletin of Irkutsk State University. Series: Mathematics, 2011, vol. 4, no. 4, pp. 45-57. (in Russian)

11. Nirenberg L. Topics in Nonlinear Functional Analysis. N.Y., American Mathematical Society, 2001.

Received November 10, 2017

УДК 517.9

DOI: $10.14529 / \mathrm{mmp} 180101$

\title{
ЗАДАЧА КОШИ ДЛЯ УРАВНЕНИЯ СОБОЛЕВСКОГО ТИПА ВЫСОКОГО ПОРЯДКА
}

\author{
А.А. Замышляева, Е.В. Бъчков \\ Южно-Уральский государственный университет, г. Челябинск, \\ Российская Федерация
}

\begin{abstract}
В статье исследована полулинейная математическая модель ионно-звуковых волн в плазме на основе разрешимости задачи Коши для абстрактного полного полулинейного уравнения соболевского типа высокого порядка. Используется теория относительно полиномиально ограниченных пучков операторов, теория дифференцируемых банаховых многообразий и метод фазового пространства. Построены проекторы, расщепляющие пространство в прямую сумму, и уравнение на два эквивалентных уравнения. Одно из уравнений определяет фазовое пространство, и его решением является функция со значениями из собственного подпространства оператора при старшей производной по времени. Решением второго уравнения является функция со значениями из образа проектора. Таким образом, были получены достаточные условия разрешимости изучаемой задачи. В качестве приложения рассмотрено уравнение четвертого порядка с сингулярным оператором при старшей производной по времени, лежащее в основе математической модели ионно-звуковых волн в плазме. Редуцировав модельную задачу к абстрактной, были получены достаточные условия существования единственного решения полулинейной математической модели ионно-звуковых волн в плазме.

Ключевые слова: уравнение соболевского типа высокого порлдка; полулинейное уравнение; полиномиальный пучок операторов; метод фазового пространства.
\end{abstract}




\section{Литература}

1. Замышляева, А.А. Вычислительный эксперимент для одной математической модели ионно-звуковых волн / А.А. Замышляева, А.С. Муравьев // Вестник ЮУрГУ. Серия: Математическое моделирование и программирование. - 2015. - Т. 8, № 2. - С. 127-132.

2. Свиридюк, Г.А. Фазовые пространства одного класса операторных полулинейных уравнений типа Соболева / Г.А. Свиридюк, Т.Г. Сукачева // Дифференциальные уравнения. -1990 . - Т. 26 , № 2. - С. 250-258.

3. Замышляева, А.А. Линейные уравнения соболевского типа высокого порядка / А.А. Замышляева. - Челябинск: Издательский центр ЮУрГУ, 2012.

4. Свиридюк, Г.А. О галеркинских приближениях сингулярных уравнений типа Соболева / Г.А. Свиридюк, Т.Г. Сукачева // Известия высших учебных заведений. Математика. 1989. - № 10. - C. 44.

5. Манакова, Н.А. О решении задачи Коши - Дирихле для уравнения Баренблатта - Гильмана / Н.А. Манакова, Е.А. Богатырева // Известия Иркутского государственного университета. Серия: Математика. - 2014. - Т. 7. - С. 52-60.

6. Манакова, Н.А. Оптимальное управление решениями начально-конечной задачи для линейной модели Хоффа / Н.А. Манакова, А.Г. Дыльков // Математические заметки. 2013. - T. 94, № 2. - C. 225-236.

7. Келлер, А.В. Задача оптимального измерения для модели измерительного устройства для модели измерительного устройства с детерминированным воздействием и инерционностью / А.В. Келлер, М.А. Сагадеева // Вестник ЮУрГУ. Серия: Математическое моделирование и программирование. - 2014. - Т. 7, № 1. - С. 134-138.

8. Свиридюк, Г.А. Фазовые пространства одного класса линейных уравнений соболевского типа высокого порядка / Г.А. Свиридюк, А.А. Замышляева// Дифференциальные уравнения. - 2006. - Т. 42, № 2. - С. 252-260.

9. Ленг, С. Введение в теорию дифференцируемых банаховых многообразий / С. Ленг. М.: Мир, 1967.

10. Замышляева, А.А. Фазовое пространство уравнения соболевского типа высокого порядка / А.А. Замышляева // Известия Иркутского государственного университета. Серия: Математика. - 2011. - Т. 4, № 4. - С. 45-57.

11. Ниренберг, Л. Лекции по нелинейному функциональному анализу / Л. Ниренберг. - М.: Мир, 1980.

Алена Александровна Замышляева, доктор физико-математических наук, доцент, кафедра «Прикладная математика и программирование», ЮжноУральский государственный университет (г. Челябинск, Российская Федерация), zamyshliaevaaa@susu.ru.

Евгений Викторович Бычков, кандидат физико-математических наук, кафедра «Уравнения математической физики», Южно-Уральский государственный университет (г. Челябинск, Российская Федерация), bychkovev@susu.ru.

Поступила в редакиию 10 ноября 2017 г. 